\title{
Rapid Detection of Mycobacterium tuberculosis Complex in Tissues by Using the Nested PCR
}

Jung-Yeon Park and Byoung-Seon Yang

Department of Medical Laboratory Science, Jinju Health College, Jinju 52655, Korea

\section{Nested PCR을 이용하여 조직으로부터 Mycobacterium tuberculosis Complex 신속검출}

\author{
박정연, 양병선 \\ 진주보건대학교 임상병리과
}

\begin{abstract}
Due to the increase in incidence of infection of Mycobacterium tuberculosis complex (MTC), it is imperative that a rapid diagnosis accompanies the handling of MTC. This is due to the three to eight weeks it takes to culture Mycobacteria, and the lack of sensitivity of microscopic examination of AFB. Recently, nested PCR has been used to detect and diagnose mycobacteria. It is especially useful in complementing diagnosis by histological extra pulmonary. After culturing all the specimens and practicing the nested PCR, we did comparison analysis between nested PCR and culture. There were 76 specimens, 31 of which were positive. Of the 31 positive specimens in culturing, only 22 were positive in nested PCR. Of the 45 negative specimens, 36 were negative in nested PCR. As a result, Sensitivity was $71 \%$ and specificity was $80 \%$. Furthermore, the positive predictive value was $71 \%$ and negative predictive value was $80 \%$. These results indicate that nested PCR based techniques are sensitive, specific, and rapid methods for the detection of MTC.
\end{abstract}

Keywords: Mycobacterium tuberculosis, Positive predictive value, Nested PCR

This is an Open Access article distributed under the terms of the Creative Commons Attribution Non-Commercial License (http://creativecommons.org/licenses/by-nc/4.0) which permits unrestricted non-commercial use, distribution, and reproduction in any medium, provided the original work is properly cited.

Copyright @ 2015 The Korean Society for Clinical Laboratory Science. All rights reserved.
Corresponding author: Jung-Yeon Park Department of Medical Laboratory Science, Jinju Health College, Jinju 52655, Korea Tel: 82-55-740-1851

E-mail: park1408jy@hanmail.net

Received: October 6, 2015

Revised: October 29, 2015

Accepted: October 30, 2015

\section{서 론}

결핵은 Mycobacterium tuberculosis, M.africanum, M.bovis, M.microti, M.caprae, M.mungi, M.orygis, M.pinnipedii 그리고 M.cannetii을 포함한 M.tuberculosis complex (MTC)에 의해 일 으키는 만성감염질환이다(Brosch 등, 2002; Cristina 등, 2014).

과거 5년 동안, 개발도상국과 후진국에서 결핵균과 비결핵균의 감염이 증가되었다. 개발도상국가에서 결핵균 감염증의 주된 증가 원인은 Human immunodeficiency virus (HIV) 감염, 결핵균의 높은 유병률, 면역억제제 사용 그리고 다재내성 mycobacteria 출
현 때문이다. 그러므로 민감하며 신속하고 정확한 결핵균의 검출은 결핵의 진단과 치료에 필수적이다(WHO, 1995; WHO, 1996).

액체배지와 고체배지에 결핵균을 배양하는 방법이 표준화 방법 으로 사용되어 왔지만, 결핵균을 배양 하는 데는 3주에서 8주정도 의 오랜 배양기간이 걸린다. 그리고 항산성 염색에 의한 현미경적 진단 방법은 임상검체 $1 \mathrm{~mL}$ 당 10,000개의 세균을 필요로 한다 (Bannister 등, 1996). 특히 결핵이 의심되는 조직 검체의 경우 배 양하기가 어려워 조직의 형태학적 관찰이나 항산성 염색에 의한 현 미경적 방법으로 진단하기 때문에 mycobacteria의 검출을 위한 빠르고 정확한 방법이 필요하다(Eisenach 등, 1990; Osaki 등, 
1997).

Hence 등(1995)은 $65 \mathrm{kDa}$ heat shock protein (HSP)의 383 bp mycobacterial DNA 유전자를 표적으로 한 polymerization chain reaction $(\mathrm{PCR})$ 방법을 사용하였다. 최근에는 DNA가 coding된 mycobacteria 항원, ribosomal RNA, Mycobacterium tuberculosis complex의 반복 염기서열을 대상으로 PCR을 실시 하였다(Boddinghaus 등, 1990; Jonas 등, 1993). 대부분의 병원에 서는 PCR방법을 호흡기 검체, 소변 등 배양 검체와 고정 되지 않은 조직검체에 사용하였다(Hermans 등, 1998; Thierry 등, 1990).

Nested PCR방법은 두쌍의 primer을 사용하며 첫 번째 primer 로 유전자의 외측부위를 증폭시킨 후 두 번째 primer로 첫 번째 primer로 증폭시킨 유전자를 표적유전자로 사용하여 증폭시킨다. Nested PCR의장점은 특이유전자의 특이성 및 감수성을 증가시킨다.

본 연구에서는 76개의 조직검체를 nested PCR을 실시하였고 배양결과와 함께 비교 분석 하였다

\section{재료 및 방법}

\section{1. 재료}

2014년 3월부터 7월까지 부산소재의 B병원 으로부터 채취한 lung 37 개, bronchus 2 개, omentum 1 개, lymph node 12 개, colon 2 개, soft tissue 7 개, bone marrow 1 개, liver 1개, breast 1 개, skin 3 개, jonint knee 2개, urinary blader 1개, esophagus 1 개, chest wall 1 개, duodenum 1 개, prostate 1 개, pleura 1 개, kidney 1 개의 검체 총 76 개의 조직 검체를 대상으로 배양과 nested PCR을 실시하였다.

\section{2. 방법}

\section{1) 결핵균 도말 및 배양}

조직검체를 직접 슬라이드에 도말하여 Ziel-Neelsen 염색을 실 시하였다. 배양용은 항산균 도말검사 후 나머지 검체를 $3 \%$ Ogawa 배지에 접종하여 $37^{\circ} \mathrm{C}$ 에서 최대 8주간 관찰하였다.
2) Nested $P C R$

포르말린에 고정된 파라핀 포매 조직을 $5 \mu \mathrm{m}$ 로 자른 후 슬라이 드 글라스에 부착시키고 자일렌을 이용해서 탈 파라핀 시켰다. Alcohol (99-50\%)을 이용해서 용매를 제거한 후 탈수 시켰다. 100 $\mu \mathrm{L}$ 소화용액 $(200 \mu \mathrm{g} / \mathrm{mL}$ proteinase $\mathrm{K}, 50 \mathrm{mM}$ tris $/ \mathrm{HCl}, \mathrm{pH} 8.5$, $1 \mathrm{mM}$ ethylenediaminetetra acetic acid, $0.5 \%$ Tween 20)을 사 용하여 슬라이드 글라스에 있는 검체를 용해시킨 다음 이 혼합액을 $56^{\circ} \mathrm{C}$ 에서 24 시간 방치 시켰다. 혼합액을 $94^{\circ} \mathrm{C}$ 에서 10 분 반응 시 켜 proteniase $\mathrm{K}$ 에서 활성을 정지시켜 $\mathrm{PCR}$ 반응 주형 $\mathrm{DNA}$ 로 사용 하였다. 1차 PCR master 혼합액(100 pmol A1 forward primer, A2 reverse primer, 100 ng DNA, $2 \mathrm{mM}$ dNTP, $25 \mathrm{mM} \mathrm{MgCl}_{2}$, 10X reaction buffer, 2.5 unit Ta $q$ DNA polymerase) 최종부피 $20 \mu \mathrm{L}$ 가 되도록 하여 PCR (Perkin-Elmer Centus Corp., USA)을 실시하였고 2차 PCR master 혼합액(100 pmol B1 forward primer, B2 reverse primer, $100 \mathrm{ng}$ DNA, $2 \mathrm{mM}$ dNTP, $25 \mathrm{mM}$ $\mathrm{MgCl}_{2}, 10 \mathrm{X}$ reaction buffer, 2.5 unit Taq DNA polymerase) 최 종부피 $20 \mu \mathrm{L}$ 가 되도록 하여 1차 PCR 생성물을 $1 \mu \mathrm{L}$ 을 사용하여 표적으로 2차 PCR (Perkin-Elmer Centus Corp., USA)을 실시하 였다(Table 1).

1 차 $\mathrm{PCR}$ 은 1 시간 40 분정도 소요되었고 $94^{\circ} \mathrm{C}$ 에서 15 분간 1 cycle 실시, $94^{\circ} \mathrm{C}$ 에서 30 초, $58^{\circ} \mathrm{C}$ 에서 30 초, $72^{\circ} \mathrm{C}$ 에서 30 초로 총 $30 \mathrm{cycle}$ 실시, 마지막으로 $72^{\circ} \mathrm{C} 60$ 초 1 cycle 실시하였다. 2차 $\mathrm{PCR}$ 은 $94^{\circ} \mathrm{C}$ 에서 30 초, $54^{\circ} \mathrm{C}$ 에서 30 초, $72^{\circ} \mathrm{C}$ 에서 30 초에서 35 cycle 실시하였다. PCR 결과를 확인하기 위해서, PCR 산물은 $1.5 \%$ agarose gel에서 40 분간 전기영동 하였으며 전기영동 후 ethidium bromide $(50 \mu \mathrm{g} / \mathrm{mL})$ 에 10분간 염색하여 DW로 세정 후 BioDoc- $14^{\mathrm{TM}}$ Imaging system (UVP, UK)에 옮겨 PCR 증폭산물 의 유무와 크기를 관찰하고 사진 촬영하였다.

\section{결 과}

76개의 조직 검체를 사용하여 항산성염색과 배양 그리고

Table 1. Primer sequence for $P C R$

\begin{tabular}{|c|c|c|c|c|}
\hline Primer & Primer sequene & Gene (product size) & $\begin{array}{l}\text { Annealing } \\
\text { temperature }\end{array}$ & PCR Cycle \\
\hline $\mathrm{A} 1$ & 5'-GAGATCGAGCTGGAGGATCC-3'sense & $65 \mathrm{kDa}$ heat shock protein & $58^{\circ} \mathrm{C}$ & 30 \\
\hline A2 & 5'-AGCTGCAGCCCAAAGGTGTT-3'antisense & Primary PCR (383 bp) & & \\
\hline B1 & 5'-TAGCCAAGAAGACCGATGAC-3'sense & $65 \mathrm{kDa}$ heat shock protein & $54^{\circ} \mathrm{C}$ & 35 \\
\hline B2 & 5'-AATCTGCTCCTTGGTCTCGA-3'antisense & Nested PCR (203 bp) & & \\
\hline $\mathrm{C} 1$ & 5'-CCTGCGAGCGTAGGCGTCGG-3'sense & IS $6110(123 \mathrm{bp})$ & $58^{\circ} \mathrm{C}$ & 35 \\
\hline $\mathrm{C} 2$ & 5'-CTCGTCCAGCGCCGCTTCGG-3'antisense & & & \\
\hline D1 & 5'-CAACTTCATCCACGTTCACC-3'sense & $\beta$-Globin (268 bp) & $58^{\circ} \mathrm{C}$ & 20 \\
\hline D2 & 5'-GAAGAGCCAAGGACAGGTAC-3'antisense & & & \\
\hline
\end{tabular}


nested PCR을 실시하였다. 76 개 검체 중 37개의 폐 검체(48.5\%), 39 개의 폐외 검체(51.5\%)를 사용하여 검사를 실시하였다.

\section{1. 배양과 nested $\mathrm{PCR}$ 결과 비교 분석}

76 개의 검체 중 배양 결과 31 개(41\%)의 검체가 양성, 45 개 (59\%)의 검체가 음성으로 나타났다. 이중에 배양결과 양성인 31 개 의 검체를 nested PCR을 실시한 결과 양성으로 나온 검체는 22 개 (71\%) 검체가 양성으로 나타났고, 배양 결과 음성인 45 개의 검체 중 36 개 $(80 \%)$ 검체가 음성으로 나타났다. 조직검체 MTC검출에 대 한 PCR민감도는 $71 \%$, 특이도는 $80 \%$ 로 나타났고, 양성 예측율은 배양 양성 31 개 검체 중 PCR결과 양성으로 나타낸 22개의 검체로 $71 \%$ 로 나타났다. 음성예측률은 PCR결과 배양 음성 45 개의 검체 중 PCR결과 음성으로 나타낸 32 개의 검체로 $80 \%$ 로 나타났다(Fig. 1, Table 2).

\section{2. 검체에 따른 배양과 Nested PCR결과 비교 분석}

총 76 개의 검체를 37 개의 폐 검체와 39 개 폐 외의 검체로 나누어 nested PCR과 비교 분석 하였다. 폐 검체의 경우 37 개의 검체 중 배 양 결과 16 개( $43 \%)$ 의 검체가 양성, 21 개(57\%)의 검체가 음성으로 나타났다. 이중에 배양결과 양성인 16 개의 검체를 nested PCR을

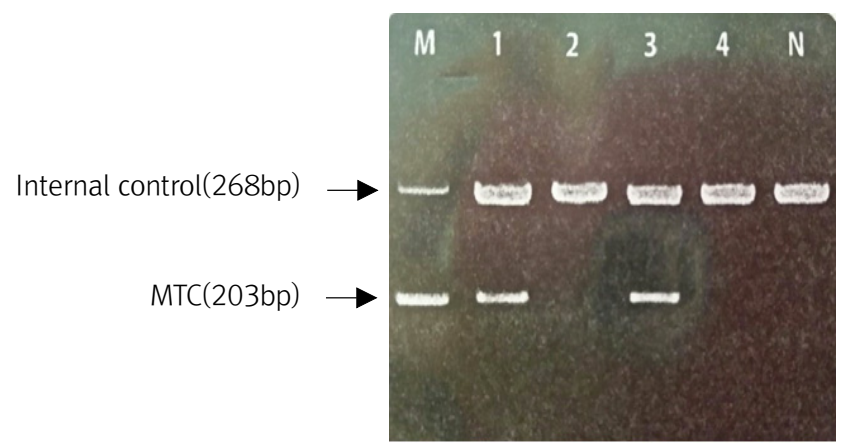

Fig. 1. Electrophoresis of the amplified products of MTC by PCR in a $1.5 \%$ agarose gel. $M$, size marker; Lanes 1 and 3, positive; lanes 2 and 4, negative; lane $\mathrm{N}$, negative control. The amplified products and their sizes are indicated on the left.

Table 2. Results of amplification of DNA fragment in mycobacteria of the tuberculosis complex

\begin{tabular}{lccc}
\hline \multirow{2}{*}{ PCR } & \multicolumn{2}{c}{ Culture results } & Total \\
\cline { 2 - 3 } & Positive & Negative & \\
\hline Positive & 22 & 9 & 31 \\
Negative & 9 & 36 & 45 \\
Total & 31 & 45 & 76 \\
\hline
\end{tabular}

Sensitivity, $71 \%$ (22 of 31); specificity, $80 \%$ (36 of 45); positive predictive value, $71 \%$ (22 of 31 ); negative predictive value, $80 \%$ (36 of 45).
실시한 결과 양성으로 나온 검체는 11 개(69\%) 검체가 양성으로 나 타났고, 배양 결과 음성인 21 개의 검체 중 16 개( $76 \%$ ) 검체가 음성 으로 나타났다. 폐검체 MTC검출에 대한 PCR민감도는 $69 \%$, 특이 도는 76\%로 나타났고, 양성 예측율은 배양 양성 16 개 검체 중 PCR 결과 양성으로 나타낸 11 개의 검체로 $69 \%$ 로 나타났다. 음성예측 률은 PCR결과 배양 음성 21개의 검체 중 PCR결과 음성으로 나타 낸 16개의 검체로 $76 \%$ 로 나타났다(Table 3).

폐 외의 검체의 경우 39 개의 검체 중 배양 결과 15 개(38\%)의 검 체가 양성, 24 개(62\%)의 검체가 음성으로 나타났다. 이중에 배양 결과 양성인 15 개의 검체를 nested PCR을 실시한 결과 양성으로 나온 검체는 12 개 $(80 \%)$ 검체가 양성으로 나타났고, 배양 결과 음성 인 24 개의 검체 중 18 개 $(75 \%)$ 검체가 음성으로 나타났다. 폐외 검 체 MTC검출에 대한 PCR민감도는 $80 \%$, 특이도는 $75 \%$ 로 나타났 고, 양성 예측율은 배양양성 18 개 검체 중 PCR결과 양성으로 나타 낸 12 개의 검체로 $66 \%$ 로 나타났다. 음성예측률은 PCR결과 배양 음성 21 개의 검체 중 PCR결과 음성으로 나타낸 18 개의 검체로 $85 \%$ 로 나타났다(Table 4).

\section{고 찰}

결핵 진단 분야에 있어서 PCR방법을 이용한 분자 유전학적 연 구가 활발히 진행되어왔다. 특히 폐결핵 진단을 위한 객담과 기관 지 세척액 검체에서 PCR 방법을 실시하였다(Jang, 2015). 폐 이외

Table 3. Results of amplification of DNA fragment in mycobacteria of the tuberculosis complex using pulmonary

\begin{tabular}{lccc}
\hline \multirow{2}{*}{ PCR } & \multicolumn{2}{c}{ Culture results } & \multirow{2}{*}{ Total } \\
\cline { 2 - 3 } & Positive & Negative & \\
\hline Positive & 11 & 5 & 16 \\
Negative & 5 & 16 & 21 \\
Total & 16 & 21 & 37 \\
\hline
\end{tabular}

Sensitivity, $69 \%$ (11 of 16 ); specificity, $76 \%$ (16 of 21 ); positive predictive value, $69 \%$ (11 of 16 ); negative predictive value, $76 \%$ (16 of 21).

Table 4. Results of amplification of DNA fragment in mycobacteria of the tuberculosis complex using nonpulmonary

\begin{tabular}{lccc}
\hline \multirow{2}{*}{ PCR } & \multicolumn{2}{c}{ Culture results } & \multirow{2}{*}{ total } \\
\cline { 2 - 3 } & positive & negative & \\
\hline positive & 12 & 6 & 18 \\
negative & 3 & 18 & 21 \\
total & 15 & 24 & 39 \\
\hline
\end{tabular}

Sensitivity, $80 \%$ (12 of 15 ); specificity, $75 \%$ (18 of 24 ); positive predictive value, $66 \%$ (12 of 18 ); negative predictive value, $85 \%$ (18 of 21). 
의 검체에서 결핵진단을 위해 흥수액이나 소변과 같은 체액검체, 조직검체, 세침흡입검체 등에서 PCR검사를 실시하였다(De 등, 1990). 폐 외의 검체에서 결핵의 진단은 주로 생검을 통한 조직괴사 를 동반한 만성육아종성 병변이 중요한 소견이다(Choi 등, 2006). 현재까지 국내에서는 건락성괴사를 동반한 만성육아종성 염증 동 반 시 결핵의 가능성이 가장 크다고 알려져 있지만, 만성육아종성 병변이 지속적인 항원자극에 대한 면역학적 반응이라 진균성 감염 이물질에 대한 반응 또는 매독등과 같은 여러 다른 요인들의 가능 성도 배제할 수 없다. 또한 현미경적 소견 상 육아종성 염증 소견과 균 자체의 확진을 위한 항산성균 도말 검사, 결핵균 배양 검사와의 상관관계는 그리 높지 않아 조직 검체의 결핵 진단을 보안해 줄 수 있는 또 다른 검사 방법으로 민감도가 높은 PCR의 방법에 대한 관 심이 증가되었다(Choi 등, 2006).

본 연구에서는 76 개의 조직 검체를 이용해서 배양과 $\mathrm{PCR}$ 을 실 시하였다. MTC 배양은 31 개의 검체에서 양성을 보였지만 $\mathrm{PCR}$ 방 법에선 9개의 검체에서 음성을 나타났다. Chan 등(1998)의 보고 에 의하면 formalin 고정액, 탈회 등이 DNA를 분해시켜 PCR반응 을 억제 한다고 하였다. 또한 빼 같은 경우 $\mathrm{DNA}$ 를 추출하기 힘든 검 체이기 때문에 배양에서는 양성으로 나타나지만 PCR방법에선 음 성을 나타낼 수 있다. 또 다른 예로 채취한 부위에 따라서 배양은 양 성이지만 PCR에서 음성을 보일 수 있다(Totsch 등, 1996). 반면에, 배양결과는 음성이지만 PCR방법에서 양성으로 나타나는 경우가 있다. 이 경우는 결핵약을 투여해서 이미 결핵균이 죽었지만 DNA 는 남아있어서 배양에서는 균이 자라지 않지만 PCR 방법 결과 양 성으로 나타날 수 있다(Brisson-Noel등, 1991; Savic 등, 1992).

또한 피부암과 같은 병을 않고 있을 때 파괴된 조직으로부터 $\mathrm{DNA}$ 가 방출될 수 있는데 이 경우에 PCR은 양성, 배양결과는 음성 으로 나타났다(Vago 등, 1998).

배양 결과 양성으로 나타난 검체 31 개의 검체 중 $\mathrm{PCR}$ 방법 양성 으로 나타난 검체는 22 개로 $\mathrm{PCR}$ 의 방법의 민감도가 $71 \%$, 그리고 배양 결과 음성으로 나타난 검체 45 개 검체 중 PCR음성으로 나타 난 검체 36 개 PCR의 방법의 특이도이 $80 \%$ 로 나타났다. 또한 양성 예측률과 음성예측률은 각각 $71 \%, 80 \%$ 를 보였다. Frevel 등 (1999)의 보고에 의하면 PCR방법의 의한 감수성이 $90 \%$, 특이성은 92\%를 보여 본 연구 결과와 비교할 때 본 연구가 민감도와 특이도 가 낮았으나 특이도에서 높은 수치를 나타냈다. 앞으로 조직검체의 경우 한 부위 보다는 다양한 부위를 채취하여 DNA을 추출하고, 빼 검체의 경우 많은 양의 검체를 사용하여 $\mathrm{DNA}$ 을 추출하면 위 음성 문제를 해결할 수 있다고 생각 된다. Nested PCR방법은 조직검체 로부터 신속하고 정확하게 $\mathrm{MTC}$ 을 검출 할 수 있고, 빠르게 결핵균 치료를 할 수 있는 정보를 제공할 수 있다.

\section{요 약}

결핵균의 감염이 증가함에 따라 결핵을 진단하고 치료하는 데 있어서 빠르고 민감한 진단방법이 필수적이다. Mycobacteria를 배양하는 것이 적어도 3 주에서 8 주정도 기간이 걸리고, 또한 $\mathrm{AFB}$ 의 현미경적 검경의 민감도가 낮다. 최근에는 PCR방법이 결핵균을 검출하고 진단하는데 사용되고 있다. 특히 병리조직학적 폐 외 감 염의 진단을 하기 위해 실시하고 있다.

병원에서 76개의 조직검체를 배양하고 nested PCR을 실시하여 배양결과와 비교 분석 하였다. 76 개의 조직검체 중 배양 결과 양성 인 검체가 31 개, 음성으로 나온 검체가 45 개로 나타났다. 배양결과 양성인 31개 검체 중 nested PCR을 실시해서 양성으로 나온 검체 22 개( $71 \%)$ 가 양성으로 나타났고, 배양결과 음성인 45 개 검체 중 nested PCR을 실시해서 음성으로 나온 검체는 36개(80\%)로 나타 났다. nested PCR의 민감도는 $71 \%$ 이고 특이도는 $80 \%$ 이다. 또한 양성 예측률은 $71 \%$ 음성 예측률은 80\%로 나타났다. Nested PCR 방법은 민감하고 신속하게 MTC을 검출 할 수 있다.

\section{Acknowledgements: None \\ Funding: None \\ Conflict of interest: None}

\section{References}

1. Boddinghaus B, Rogall T, Flohr T, et al. Detection and identification of mycobacteria by amplification of rRNA. J Clin Microbiol. 1990, 28:1751-1759.

2. Brisson-Noel A, Nguyen S, Bonete R, et al. Diagnosis of tuberculosis by DNA amplification in clinical practice evaluation. Lancet. 1991, 338:364-366.

3. Brosch R, Gordon SV, Marmiesse M, Brodin P, Buchrieser C, Eiglmeier K, et al. A new evolutionary scenario for the Mycobacterium tuberculosis complex. Proc Natl Acad Sci. 2002, 99:3684-3689.

4. Chan CM, Yuen KY, Chan KS, et al. Single-tube nested PCR in the diagnosis of tuberculosis. J Clin Pathol. 1996, 49:290-294.

5. Choi WS, Shin SY, Kim JO, Kim MS, Lee HY. Usefulness of automated PCR test of the detection of Mycobacterium tuberculosis in fresh biopsy tissues. Tuberc Respir Dis. 2006, 61:54-59.

6. De Wit D, Steyn L, Shoemaker S, et al. Direct detection of Mycobacterium tuberculosis in clinical specimens by DNA amplification. J Clin Microbiol. 1990, 28:2437-2441.

7. Cristina P. Ana Luiza A.R. Klaudia S.G. Carlos A.N. et al. Direct detection of Mycobacterium tuberculosis complex in bovine and bubaline tissues through nested-PCR. 2014, Bra J Micro. 2014, 45:6333-640.

8. Eisenach KD, Cave MD, Bates JH, et al. PCR amplification of a 
repetitive DNA sequence specific for Mycobacterium tuberculosis. J Infect Dis. 1990, 28:1204-1213.

9. Frevel, K L schafer, M Totsch, W Bocker, B Dockhorn-Dworniczak et al. PCR based detection of mycobacteria in paraffin wax embedded material routinely processed for morphological examination. J Clin Patholl. 1999, 52:283-288.

10. Groups at risk, WHO report on the tuberculosis epidemic 1996. Geneva. World Health Organization, 1996.

11. Hance A, Grandchamp B, Levy-Frebauit V, et al. Detection and identification of Mycobacteria by amplification of mycobacterial DNA. Mol Microbiol. 1989, V 3:843-849.

12. Hermans PW, Schuitema AR, Van Soolingen D, et al. Specific detection of Mycobacterium tuberculosis complex strains by polymerase chain reaction. J Clin Microbiol. 1990, 28:12041213.

13. Jang HS. Identification of Mycobacteria using polymerase chain reaction and sputum sample. Korean J Clin Lab Sci. 2015, 47(2): 83-89.

14. Jonas V, Alden MJ, Curry JI, et al. Detection and identification of Mycobacterium tuberculosis directly from sputum sediments by amplification of rRNA. J Clin Microbiol 1993, 31:2410-2416.

15. Osaki M, Adanchi H, Gomyo Y, et al. Detection of mycobacterial DNA in formalin-fixed, paraffin-embedded tissue speci- mens by duplex polymerase chain reaction: application to histopathologic diagnosis. Mod Pathol. 1997, 10:78-83.

16. Savic B, sjobring U, Alugupalli S, et al. Evaluation of polymerase chain reaction, tuberculostearic acid analysis, and direct microscopy for the detection of Mycobacterium tuberculosis in sputum. J Infect Dis. 1992, 166:1177-1180.

17. Shinnick TM. The 65-kilodalton antigen of Mycobacterium tuberculosis. J Bacteriol. 1987, 169:1080-1088.

18. Thierry D, Brrison-Noel A, Vincent-Levy-Frebault V, et al. Characterization of a Mycobacterium tuberculosis insertion sequence, IS6110, and its application in diagnosis. J Clin Microbiol. 1990, 28:2668-2673.

19. Totsch M, Bocker W, Brommelkamp E. Diagnostic value of different PCR assay for the detection of mycobacterial DNA in granulomatous lymphadenopathy. J Pathol. 1996, 178:221-226.

20. Treatment of tuberculosis guidelines for national programmers. Geneva: World Health Organization, 1995.

21. Vago L, Barberis M, Gori A, et al. Nested Polymerase chain reaction for Mycobacterium tuberculosis IS6110 sequence on formalin-fixed paraffin-embedded tissues with granulomatous diseases for rapid diagnosis of tuberculosis. Am J Clin Pathol. 1998, 109:411-415. 